\title{
Renal Pelvis and Ureter Urothelial
} Carcinoma

National Cancer Institute

\section{Source}

National Cancer Institute. Renal Pelvis and Ureter Urothelial Carcinoma. NCI Thesaurus.

Code C7716.

A transitional cell carcinoma that arises from the renal pelvis and ureter. 